Revista de Filosofía

ISSN: 0034-8244

https://dx.doi.org/10.5209/resf.68164

\title{
Una ética más allá del Bien y del Mal, entre Fichte y Deleuze
}

\author{
Julián Ferreyra ${ }^{1}$
}

Recibido: 20 de julio de 2017 / Aceptado: 28 de enero de 2019

Resumen. Deleuze considera a Fichte un moralista, que por tanto juzga con un criterio que trasciende el punto de vista del sujeto concreto y corporal. Sin embargo, teniendo en cuenta la doctrina de los impulsos presente en la Sittenlehre de Fichte, es posible considerarlo ético en sentido deleuziano: el valor depende del aumento de potencia emergente de composiciones o armonías. Por otra parte, en Deleuze las leyes de composición y las relaciones constitutivas no son afirmadas dogmáticamente, sino como fruto de un proceso genético rigurosamente determinado entre Ideas e intensidades individuantes. Palabras clave: Deleuze; Fichte; ética; perspectivismo; composición y armonía.

\section{[en] Ethics beyond Good and Evil, between Fichte and Deleuze}

\begin{abstract}
Deleuze considers Fichte a moralist, which therefore judges with a criteria that transcends the point of view of the concrete and embodied subject. However, considering his theory of drives in Fichte's Sittenlehre, it is possible to consider him as ethic in the Deleuzian sense: value depends on the augmentation of power that emerges from the compositions or harmonies. On the other hand, in Deleuze the laws of composition and the constitutive relations are not posited in a dogmatic way, but are the product of a thoroughly determined genetic process through Ideas and individuating intensities.
\end{abstract} Key words: Deleuze; Fichte, Ethics; perspectivism; composition and harmony.

Sumario: 1. De lo hipotético a lo moral: la lectura de Gueroult; 2. Moralismo: más acá del Bien y del Mal; 3. Un Fichte moral: el destino fuera del mundo; 4. Un Fichte ético: el destino en el mundo; 5. La tipología como segunda vida de los subjetivo; 6 . La aplicabilidad de la ética deleuziana; 7. Conclusión: una nueva armonía; 8 . Referencias bibliográficas.

Cómo citar: Ferreyra, J. (2020): “Una ética más allá del Bien y del Mal, entre Fichte y Deleuze”, en Revista de Filosofia 44 (2), 9-25.

1 djulianferreyra@gmail.com 
Entre las objeciones que Deleuze dirige a la historia de la filosofía se encuentra en un lugar eminente la de "moralismo". Esta objeción no debe confundirse-como algunos intérpretes lo han hecho- ${ }^{2}$ con un desinterés por la filosofía práctica o abandono de la reflexión sobre los criterios de nuestra acción en el mundo, en favor del libre fluir, la incertidumbre y el azar (en el límite, "relativismo, escepticismo e incluso nihilismo", Jun, 2011, p. 89), dado que las críticas a la moral están acompañadas por una reivindicación constante de la ética. Tal contraposición está expresada en la fórmula nietzscheana "más allá del Bien y del Mal no quiere decir más allá de lo bueno y lo malo" (Deleuze, 1962, p. 139; 1981, p. 34).

En estas páginas nos proponemos analizar el significado preciso de este posicionamiento - frecuentemente vulgarizado- a partir de la continuidad entre la interpretación que Deleuze realiza de Nietzsche y Spinoza con su propia ontología fundamental, y la confrontación con Johann Fichte, uno de los filósofos a los cuales acusa explícitamente de moralismo. El Yo fichteano sería un "imperativo de orden eminentemente moral" que lo llevaría a traicionar y desnaturalizar el verdadero movimiento del pensamiento (Deleuze, 1968a, p. 254). Veremos que, si bien algunos desarrollos del autor de la Doctrina de la ciencia justifican atribuirle tal moralismo, la vertiente interpretativa predominante (Breazeale, Wood, Fonnesu, Binkelmann entre otros) lo hace afín a la ética tal como Deleuze las caracteriza - y que sólo así cumple el requisito de la inmanencia.

Desde la perspectiva deleuziana, la confrontación con Fichte permite diagnosticar algunos riesgos de su postura, básicamente el dogmatismo y el naturalismo implícito en su defensa de la "ley natural". A partir del carácter genético que el orden de las relaciones spinozista toma en la ontología de Deleuze mediante el concepto de Idea (y su complementación necesaria con las leyes de la intensidad), construiremos "una concepción inmanente de la normatividad" (Jun, 2011, p. 89). ${ }^{3}$ En suma: en el pliegue entre la ética spinozista sostenida por Deleuze fundada por su ontología y la ética fichteana bien entendida, encontraremos una concepción de la filosofía práctica singularmente vigorosa.

\section{De lo hipotético a lo moral: la lectura de Gueroult}

Hay un trayecto que caracteriza para Deleuze a la historia de la filosofía, que tiene al moralismo como punto de llegada (y traición del verdadero movimiento del pensamiento). Es ese trayecto, Deleuze inscribe, explícitamente, a Fichte:

No es ilegítimo resumir así el movimiento de la filosofía, de Platón a Fichte o Hegel, pasando por Descartes (...) el punto de partida se encuentra en una «hipótesis» (...) y el

\footnotetext{
Cfr. especialmente May (1991) y Boltanski y Chiapello (2007).

Nathan Jun, especialista en estudios sobre el anarquismo contemporáneo, editó en 2011, junto con Daniel Smith, Deleuze and ethics, donde diferentes especialistas intentan rescatar una normatividad deleuziana (no moral en el sentido en el cual él mismo la comprende), contra su supuesto relativismo moral y funcionalidad al espíritu del capitalismo. La cuestión en ese libro, que es también la nuestra aquí, es mostrar que Deleuze responde satisfactoriamente a la pregunta "¿cuáles fuerzas deben ser determinadas como afirmando la vida y cuáles cómo negándola?” (May, 1991, p. 11). A diferencia de May, que no logra articular una respuesta afirmativa -por intentar buscarla desde el marco de la metaética contemporánea-, nosotros proponemos una investigación en torno a la relación puntual con la ética fichteana, de acuerdo a la metodología de la filosofía comparada.
} 
punto llegada se encuentra en una apodicticidad o imperativo de orden eminentemente moral (...) Este trayecto roza al máximo el verdadero movimiento del pensamiento, pero también lo traiciona al máximo" (Deleuze, 1968a, p. 254).

La descripción es, sin embargo, en exceso sucinta, y no permite, en sí misma, determinar si se trata de una crítica conceptual o basada en un simple prejuicio. Si se tratara de otro tipo de referencia (por ejemplo, la identidad del sujeto que expresaría la célebre fórmula $\mathrm{Yo}=\mathrm{Yo}$ ) la segunda opción sería plausible. ${ }^{4}$ Sin embargo, la referencia a la apodicticidad del juicio tético y el imperativo moral inherente al Yo distan de ser tópicos de los manuales y la divulgación filosófica de la obra de Fichte. Esto hace pensar que Deleuze tiene algo específico en mente sólo que, simplemente, no lo desarrolla (lo deja implícito, de acuerdo a su regla de "no explicar demasiado", Deleuze [1968a], pp. 314, 335). Intentemos, entonces, explicar (un poco).

Deleuze recibe a Fichte fundamentalmente a través de Martial Gueroult. Las referencias, por cierto escasas, a la obra de Fichte rara vez están acompañadas por citas directas del autor de la Doctrina de la ciencia. ${ }^{5}$ Lo más habitual es que cuando menciona a Fichte remita a La evolución y la estructura de la Doctrina de la ciencia en Fichte, publicada por Gueroult en dos tomos en 1930. Allí se observa muy claramente el mencionado trayecto del hipotetismo al moralismo. En efecto, Gueroult parte de una interpretación de las primeras páginas del Fundamento de la doctrina de la ciencia de 1794 (Fichte, 1975) según la cual el "punto de partida" es un juicio hipotético, en tanto $\mathrm{A}=\mathrm{A}$ tiene que leerse como si A entonces $\mathrm{A}^{6}$ (Gueroult, 1930, p. 127). Sin embargo "el Fundamento constituye en la Doctrina de la ciencia la filosofía teórica. Esta especulación no excluye de su ámbito la actividad práctica, pero la considera de manera subordinada" (Gueroult, 1930, p. 245). El acabamiento de un sistema filosófico que, tal como Fichte señala en repetidas ocasiones, es eminentemente práctico, sólo se encuentra, de acuerdo a Gueroult, en la Ética de 1798, siguiendo un esquema de correlaciones del Yo con el no-Yo:

La parte práctica del Fundamento estudiaba la causalidad del Yo sobre el no-Yo desde el punto de vista de la causalidad del no-Yo sobre el Yo: se trataba de encontrar una actividad del Yo que hiciera posible el choque. El sistema del derecho estudiaba la causalidad del no-Yo sobre el Yo desde el punto de vista de la causalidad del Yo sobre

4 Así hay que leer, por ejemplo, la referencia de Descombes a Fichte: “el Sujeto reinaba como Monarca absoluto, con todas las prerrogativas vinculadas al «Yo=Yo»" (Descombes, 1988, p. 242).

5 La única referencia directa a textos de Fichte tiene lugar en "La inmanencia, una vida", donde menciona la Segunda Introducción a la Doctrina de la Ciencia y la Introducción a la vida bienaventurada (Deleuze, 2003, p. 361). Para un panorama completo de la presencia de Fichte en la obra de Deleuze: AUTOR.

6 Interpretación que supone que la exposición del primer principio pone a $\mathrm{A}=\mathrm{A}$ como base del $\mathrm{Yo}_{\mathrm{o}}=\mathrm{Yo}$, cuando en realidad no es más que un recurso retórico (cualquier cosa que el lector acepte, por banal que sea, supone el principio de identidad -y, al mismo tiempo, esa identidad supone una diferencia: no es lo mismo el $\mathrm{A}^{1}$ que el $\mathrm{A}^{2}-$; si el lector acepta, por ejemplo, $\mathrm{A}=\mathrm{A}$, entonces con mucha más razón debe aceptar Yo=Yo -y la diferencia que le es por tanto intrínseca-). La cuestión de fondo es, que no podemos desarrollar aquí, es que se debe partir del Yo y que éste no es un principio quieto sino activo y productivo: tal es el sentido de la tan malentendida fórmula Yo=Yo (malentendidos que llevan a Fichte, en la Doctrina de la ciencia nova methodo, a reemplazar en la exposición el Yo=Yo por la intuición intelectual, y en la Doctrina de la ciencia 1801-1802 a volver al recurso retórico pero bajo la forma del trazado de un ángulo). En ese sentido, "el punto de partida" no sería, en términos deleuzianos, "hipotético" sino "genético". Ver la exposición del primer principio de 1794 en Fichte, 1975, pp. 14-15. Sobre la sustitución por la intuición intelectual, $c f r$. Fichte (1994). Ver el ejemplo del ángulo en Fichte (1845), pp. 3-4. Sobre la distinción deleuziana de lo hipotético y lo genético, cfr. Deleuze, 1981, p. 68. 
el no-Yo. Para hacer posible una acción libre y consciente del Yo sobre el no-Yo, hacía falta una influencia del no-Yo. El sistema de la moral estudia la causalidad del Yo sobre el no-Yo desde el punto de vista de la causalidad del Yo sobre el no-Yo (...) Es el último término de la síntesis quíntuple. Reencontramos en él todos los otros términos (Gueroult, 1930, p. 291).

El Fundamento de 1794 es para Gueroult una obra teórica, incluso en su parte práctica, porque toma el punto de vista del no-Yo y su influencia sobre el Yo. ${ }^{7} \mathrm{La}$ Doctrina de la ciencia sólo será práctica en el Fundamento del derecho natural de 1796/97 y la Ética de 1798. En el primero, ya alcanza el punto de vista del Yo, pero ahora bajo la acción del no-Yo (¿cómo actúo en un mundo hostil para ser libre?). Solamente la Ética tomará tanto el punto de vista del Yo como la acción del Yo: "En el sistema de la moral, el Yo se pone entonces definitivamente como se ponía al comienzo de la Doctrina de la ciencia, es decir como principio absoluto" (Gueroult, 1930, p. 293). Esto es lo que tiene en mente indudablemente Deleuze cuando afirma que el Yo es punto de llegada como "imperativo de orden eminentemente moral" (1968a, p. 254). El movimiento sigue el orden cronológico de aparición de los libros en un período relativamente breve (1794-1798), y parece con ello suficientemente justificado.

Sin embargo, esta lectura progresiva de la Doctrina de la ciencia como un trayecto con un punto de partida y un punto de llegada atenta contra su apropiada comprensión. ${ }^{8}$ El trayecto es solamente discursivo; en si mismo el proceso sintéticogenético se da de un golpe, fuera del tiempo, dando origen y determinación a lo temporal. Como el tiempo, todo trayecto en Fichte no es nada más que "la relación en la cual estamos obligados a poner nuestras representaciones" (Fichte, 1994, p. 192). Ontológicamente, filosofía teórica y práctica se compenetran, el Yo sólo puede comprenderse junto al no-Yo, la actividad junto a la pasividad. ${ }^{9}$ Por eso Yo es igual a Yo, porque son puestos ambos por un dinamismo que tiene lugar fuera del tiempo, fuera de la discursividad, fuera del orden de la representación. Una vez que aceptamos leer la Doctrina de la ciencia como un movimiento progresivo que parte de un punto para llegar a otro en una suerte de Bildungsroman, de alguna manera la acusación de Deleuze ya está probada. ${ }^{10} \mathrm{Si}$ hay un punto de llegada que ya existe aunque esté separado en el tiempo (o incluso después del tiempo, como la eternidad de una vida futura que sólo nos es accesible a través del sentimiento del deber), este nos trasciende. Y justamente en la trascendencia se anudan todas las críticas de Deleuze a la moral (y la de Fichte al dogmatismo). Se trata entonces, en

7 Existe abundante evidencia textual que hace poco plausible esta interpretación de Gueroult: en el $\S 5$ del Fundamento, por ejemplo, se observa cómo el Yo toma la iniciativa, incluso de limitarse, al tener que saber de sí. El Yo fichteano es principio tanto del conocer como del actuar libre.

8 Sobre el lugar de ética en la filosofía de Fichte, $c f r$. Ivaldo (1999).

9 Así lo considera Binkelmann, para quien la Ética no hace más que desarrollar uno de los aspectos de la Doctrina de la ciencia ya presente en el Fundamento (Grundlage) de 1794: "en la Sittenlehre, Fichte vuelve a tomar el punto de vista de la Grundlage" (Binkelmann, 2006, p. 11).

10 Deleuze mismo queda atrapado en su propia crítica cuando trata de reemplazar el movimiento de lo hipotético a lo apodíctico por el movimiento de lo problemático a la pregunta: termina defendiendo el imperativo "de otro tipo", y busca la respuesta a través del bizarro decisionismo impersonal de la tirada de dados nietzscheana (Deleuze, 1968a, p. 255). Pero la noción de un trayecto del problema actual a la pregunta virtual desfigura toda la relación actual/virtual, que, como muestra la lectura integral de Diferencia y repetición son estrictamente inmanentes. 
ambos autores, de desmontar esos espejismos de trascendencia, por mor de una ética inmanente.

\section{Moralismo: más acá del Bien y del Mal}

Uno de los motivos, por tanto, por los cuales para Deleuze la filosofía traiciona el verdadero movimiento del pensamiento, una y otra vez, de Platón a Fichte y Hegel, pasando por Descartes, es que el punto de llegada sea un "imperativo de orden eminentemente moral". La carga crítica, incluso despectiva, del término "moral" es ostensible y recorre toda la obra deleuziana, desde Empirismo y subjetividad, ensayo sobre la naturaleza humana según Hume de 1953 en adelante. A diferencia de otros términos que le son antipáticos (como Dios, sujeto, Estado o dialéctica), Deleuze se resiste a utilizar "moral" en un sentido positivo. ${ }^{11}$ Pero, ¿qué entiende exactamente por moral? En el pasaje de la página 254 de Diferencia y repetición, el sentido del término es sumamente vago. En el marco más general de ese libro, Deleuze califica como "moral" a la imagen dogmática del pensamiento a la que impugna en el capítulo tres, como presupuesto común a la filosofía ("de acuerdo a esta imagen, el pensamiento tiene afinidad con lo verdadero" Deleuze, 1968a, p. 172). Esta afinidad del pensamiento con lo verdadero, la persuasión generalizada de que "el pensamiento tiene una buena naturaleza y el pensador una buena voluntad", es lo que Deleuze llama allí "moral". Más adelante, atribuye una motivación "moral" a la "voluntad de eliminar los simulacros y los fantasmas" en favor de la identidad (Deleuze, 1968a, p. 341). Se trata, en esos casos, de caracterizaciones muy amplias, ya que se limitan a calificar de moral aquello que Diferencia y repetición se propone combatir: la imagen dogmática del pensamiento y la identidad, en favor de una filosofía de la diferencia: ${ }^{12}$ pero justamente por ser tan generales, corren el riesgo de transformarse ellos mismos en valores morales (como bien señala May, 1991, pp. 130-134).

Para encontrar una caracterización más específica de lo que entiende Deleuze por moral, es necesario remitirse a sus libros sobre Spinoza y Nietzsche. Allí la moral aparece como contracara, el reflejo desformado e invertido de un fenómeno más originario: la ética. La célebre frase de Nietzsche "más allá del bien y del mal no quiere decir más allá de lo bueno y lo malo" (Genealogía de la moral 61) es neural en Nietzsche y la filosofía de 1962, reaparece en Spinoza y el problema de la expresión de 1968, y vuelve a ser retomada en Spinoza, filosofia práctica de 1980 (además de ser analizada una y otra vez en sus cursos). La línea divisoria es que la moral considera que sus valores son absolutos, mientras que la ética acepta que éstos dependen de un punto de vista: "el mal es lo malo desde el punto de vista de

11 La única excepción es la frase de la Lógica del sentido donde afirma "o la moral no tiene ningún sentido, o lo lo que quiere decir, y lo único que quiere decir es: no ser indigno de lo que nos acontece" (Deleuze, 1969, p. 174).

12 Sin dudas podrían transpolarse a Fichte estas críticas: el Yo sería así una identidad que subsume las diferencias y la multiplicidad, y la Doctrina de la ciencia supondría una afinidad de los principios del pensamiento con la verdad. Esta lectura no haría sin embargo justicia el espíritu de la filosofía fichteana: el Yo necesita diferencias y multiplicidad para ponerse y actuar. Sobre las oscilaciones de Fichte respecto a la afinidad del pensamiento con la verdad y el rol de las mutiplicidades en su ontologia, $c f r$. Ferreyra (2018). Sobre la pertinencia de los desarrollos de este apartado a la ética fichteana se trabajará más abajo, tras haber presentado nuestra interpretación de la misma en el próximo apartado. 
tal o cual modo. Siendo nosotros mismos hombres, juzgamos el mal desde nuestro punto de vista; y Spinoza recuerda muchas veces que cuando habla de lo bueno y lo malo considera solamente la utilidad del hombre" (Deleuze, 1968b, p. 226). ${ }^{13}$ Pero la perspectiva no debe confundirse con algo fijo, atribuible a la posición de un sujeto inmóvil, idéntico a sí mismo y fundado en raíces eternas. "Lo bueno y lo malo no pueden ser más que el producto de una selección activa y temporaria, que debe volver a empezar" (Deleuze y Guattari, 1980, p. 16).

La perspectiva moral se deduce claramente como la contracara de la ética: la moral no toma en cuenta el punto de vista, pone a lo Bueno y lo Malo como valores trascendentes ${ }^{14}$ y juzga a través de ello a lo existente a partir de valores que no pertenecen al orden de la existencia. ${ }^{15}$ Comer corderos es malo, las aves rapaces son malas. Este razonamiento moral se generaliza y se transpola luego al mundo entero: el mundo entero me aparece como amenaza, el mundo es malo, y yo quiero un mundo mejor que lo que es (Deleuze, 1962, p. 110).

¿Qué es lo bueno y lo malo para una perspectiva? Tiene que ver con las composiciones de cuerpos y sus modos de existencia. Se trata de un criterio inescindible de nuestro modo de existir, es decir, de nuestra "relación característica": "la relación determinada en el sujeto mismo entre fuerzas de diferente naturaleza que lo componen (...) Se trata de una ética y una tipología, tipología de las fuerzas, ética de las maneras de ser correspondientes" (Deleuze, 1962, pp. 132, 138). El criterio ético (la normatividad) se basa en una evaluación de los tipos de encuentros entre cuerpos con distintas tipologías. "Lo bueno, es cuando un cuerpo compone directamente su relación con la nuestra y, en todo o en parte de su potencia, aumenta la nuestra" (Deleuze, 1981, p. 34). ${ }^{16}$ Cuando un cuerpo encuentra uno que compone con él, se dice que aumenta su potencia, cuando no se compone, se dice que ésta disminuye. No se trata por tanto de lo que "podemos hacer", sino de evaluar si aquello que podemos hacer - encontrarnos con otro cuerpo o evitarlo- aumenta o disminuye nuestra capacidad de actuar (no es facultativo sino normativo). Podemos muchas cosas que son nocivas para nosotros. ${ }^{17}$ Tales son las bases del spinozismo deleuziano para las masas, una Populärphilosophie cuyo atractivo no la exime de problemas y desafíos que exigen una complejización ontológica - que en estas páginas será fruto de la exhortación fichteana.

13 Deleuze cita en este sentido la siguiente frase de Nietzsche: "cuando los corderitos dicen entre si «estas aves de rapiña son malvadas; y quien es lo menos posible un ave de rapiña, sino más bien su antítesis, un corderito, -¿no debería ser bueno?», nada hay que objetar a este modo de establecer el ideal" (Nietzsche, 1995, p. 51).

14 Este es uno de los motivos principales por lo cuales, como veremos, la acusación deleuziana de "moralismo" en Fichte no es apropiada: no hay en el autor de la Doctrina de la ciencia un Bien trascendente.

15 "La moralidad se vuelve un concepto exteriorizado y trascendente, separado de la vida humana común", Jun (2011) p. 92. Cfr. Smith (2011), p. 124.

16 Esta concepción no implica una neutralidad evaluativa, y puede utilizarse para impugnar las conductas que habitualmente representan el Mal (eminentemente, Hitler y el nazismo). Solamente, exigen una argumentación que no se basa en el sentido común y un Mal trascendente, sino que deben mostrar en qué sentido el holocausto implicó una disminución de la capacidad de actuar de todos los involucrados (y, en general, que todos los despotismos están basados en la organización de las pasiones tristes).

17 No coincidimos por tanto con la perspectiva de Smith (2011), pp. 124-125 que confunde poder con potencia -y por tanto afección con afecto-, es decir, la perspectiva estática de lo que el cuerpo puede (las afecciones de la que es capaz) con la perspectiva dinámica del afecto (si esas afecciones aumentan o disminuyen su potencia). Sobre esta cuestión, $c f r$. Ferreyra, 2016. Problemas similares se observan en el intento de Bogue de pensar una ética inmanente (“la pregunta ética no es «¿qué debemos hacer?» sino «¿qué podemos hacer?», Bogue, 2007, p. 12). Evans sí introduce el aumento de la potencia como criterio ético (p. 92), pero ignora la importancia del punto de vista. Sobre la distinción entre afección y afecto, $c f$ r. Deleuze (2008), pp. 297-299. 


\section{Un Fichte moral: el destino fuera del mundo}

Para que hubiera un moralismo en Fichte, de acuerdo a la caracterización deleuziana que acabamos de reconstruir, el Yo debería ser un imperativo de orden eminentemente moral y trascender el orden de la existencia, haciendo abstracción de nuestras condiciones e ignorando nuestro punto de vista. Sólo así Fichte se transformaría en un "fanático moral inhumano" (Wood, 2015, p. 105). ${ }^{18}$ Ocurre que eso implicaría una grieta en los fundamentos de la Doctrina de la ciencia: Yo no sería igual a Yo, porque el Yo puro estaría escindido del empírico, limitado o finito. Pese a ello, los escritos en torno de la polémica del ateísmo son muy difíciles de leer de otra manera. ${ }^{19}$ Hay allí un moralismo antisensualista extremo: el fruto de la buena voluntad no se recoge en la vida terrenal sino en la futura (Fichte, 2011, p. 164), el punto de vista individual es irrelevante para la perspectiva moral -algo desgraciado para mí puede ser excelente para el plan del ser eterno (p. 198)-y buscar lo agradable y rehuir lo desagradable en lugar de guiarse por el bien y el mal es motivo de culpa e indignidad (p. 199). El deber manda absolutamente, al punto en que en tanto se debe, se puede necesariamente: "No se dice «debo porque puedo», sino «puedo porque debo». El que deba y qué deba [hacer] es lo primero" (Fichte, 2009, p. 143). Nuestra existencia fáctica es despreciada en nombre de un imperativo que está destinado a dominarla y conducirla. Es, por tanto, jugada por él. Nuestro destino es dominar la existencia, y hacerlo necesariamente. Y sin embargo, en cruel ironía, esa realización no puede darse en el tiempo. El destino del hombre del que hablan las Lecciones sobre el destino del sabio es "completamente inalcanzable" (Fichte, 2002, p. 59) en ese sentido: el principio moral no es transcendente, tampoco fáctico, sino transcendental.

La Sittenlehre puede ser interpretada como siendo moralista en ese sentido y, de esa manera, considerar que los desarrollos de la polémica del ateísmo no son más que la continuidad del período de Jena. ${ }^{20}$

Esta serie está necesariamente determinada desde el primer punto en el cual la persona es colocada por su naturaleza hasta el infinito, se entiende que en la idea; por tanto, está determinado en todos los casos posibles lo que el impulso puro (reine Trieb) exige en cada uno de ellos y bajo todas esas condiciones. Esa serie la podemos denominar la determinación o destino moral del ser racional finito (...) Hemos de indicar como principio de la ética lo siguiente: cumple en cada caso con tu destino [Bestimmung]; aunque se ha de contestar aún a la cuestión, ¿pero cuál es entonces mi destino? Si se expresa la proposición simple así: cumple en general con tu destino, entonces la infinitud del fin final (Endzweck) planteado se halla de igual modo también ahí, pues el cumplimento de todo nuestro destino no es posible en ningún tiempo (Fichte, Sittenlehre 141-142, el primer subrayado es mío).

De acuerdo a esta cita, el lugar en el cual la persona es colocada por su naturaleza se contrapone a su destino moral (la naturaleza coloca a cada persona humana en un sitio espacial-temporal-cultural: cada uno nace en un espacio-tiempo-cultura. De ahí

18 Si bien Breazeale (2012, p. 186) usa esta cita para invocar aquellos que postulan el rigorisimo de la moral fichteana, el argumento de Wood, como veremos, apunta a matizar tal interpretación (cfr. Wood, 2015, p. 107).

19 Se trata de la serie de escritos que van desde Sobre el fundamento de nuestra fe en un gobierno del mundo en 1798 hasta El destino del hombre de 1800.

20 Como intentó ya en su momento demostrar Hegel en Fe y saber (2007), pp. 135-164. 
debe partir para realizar su impulso moral, de manera que cada uno tiene determinado el suyo, pues ha de responder y resolver sus circunstancias particulares). Desde esta interpretación (que por cierto pondremos inmediatamente en duda), el deber como principio de la ética, como fin final (Endzweck) y destino (Bestimmung) del ser racional finito parece trascender y contraponerse a las condiciones de nuestra existencia, que son temporales e imbricadas con la naturaleza, inescindibles del mundo sensible. El destino, siempre desde esta a nuestro entender sesgada interpertación, no es posible en ningún tiempo; sólo se realizará fuera del tiempo. Pasajes como estos apuntan a una continuidad con los escritos de la polémica del ateísmo.

Sin embargo existe en la filosofía de Fichte de Jena una tensión constitutiva (cuya Verschmelzung encierra su sentido último). Esa tensión se observa en el término Bestimmung $^{21}$ que, por una parte, apunta a un fin, incluso a un llamado divino que lo escinde del presente e incluso, en última instancia, del mundo (que, por su parte se rige por las leyes naturales y está plagado de una injusticia real que parece contraponerse a la justicia ideal); pero al mismo tiempo la Bestimmung es la función de algo, su determinación, lo que ese algo es. Por ello afirma Fonnesu que "con el concepto de «Bestimmung» Fichte piensa haber resuelto el problema de la síntesis entre la parte sensible y la racional del hombre" (1999, p. 266) (esta es es su tarea: la de transformar el mundo según las exigencias del Yo libre]. La traducción aceptada por "destino" refuerza el lado meramente racional, la idea de que el impulso puro, moral, trasciende a las condiciones naturales, imponiéndole un fin que no puede nunca alcanzar en el tiempo (en el sentido de que siempre estamos en camino, que debemos siempre esforzarnos por configurar un mundo justo y en paz). Tal énfasis hace parecer como si "un genio maligno hubiera implantado en esos desdichados la inquebrantable aspiración a lo imperecedero sólo para divertirse con sus incesantes esfuerzos en pos de aquello que siempre se le escapa" (Fichte, 2011, p. 153): la aspiración divina de nuestro propio ser, que alcanzamos progresivamente y nunca con plenitud.

\section{Un Fichte ético: el destino en el mundo}

Sin embargo, es posible hacer énfasis en la otra interpretación de Bestimmung, según la cual ésta es nuestra determinación, lo que constituye lo que somos (eso es: somos sobre todo libertad, acción, no cosa). Dado que en Fichte lo que somos no es un ser fijo y quieto sino una actividad, esta interpretación tiene la ventaja de tomar en cuenta ambos sentidos de la palabra, y permite sintetizar la parte sensible y racional del hombre: ${ }^{22}$ la tarea es justamente alcanzar la síntesis plena de Yo y mundo, pero no en el sentido de someternos al mundo, sino de realizar plenamente el modo de ser de la libertad y de sus fines. Desde esta perspectiva, el "fuera del tiempo" no necesariamente implica que debe desarrollarse después del tiempo vulgar (tras el fin de nuestra existencia empírica). Fuera del tiempo puede querer decir que es ontológicamente atemporal (como considera Fichte el desarrollo de la Doctrina de

21 Que Fichte escoge para el titulo de dos obras de divulgación muy importantes: Die Bestimmung der Gelehrten (1794) y Die Bestimmung des Menschen (1800), que se considera el cierre de su etapa vinculada a la polémica del ateísmo.

22 En la línea de Fonnesu, quien enfatiza la importancia de las acción real (wirkliche Handeln) en el mundo sensible para la ética fichteana (1999, p. 261). 
la ciencia) pero no por ello es trascendente al tiempo, sino que es una condición inmanente, trascendental y genética (en ese sentido el tiempo se deduce de los principios). ${ }^{23}$ Es en el tiempo, pero no se alcanza plenamente en ningún momento del tiempo. Así, se entrelaza con el tiempo y sus avatares, de la misma manera en que en la Doctrina de la ciencia el Yo se entrelaza con el Yo a través de la quíntuple síntesis.

"Lo que el hombre debe, puede", desde esta perspectiva, no son "palabras vacías generales" como acusaba Hegel (1970b, p. 235), sino que indican la tarea de la filosofía práctica. En efecto, si la clave de la lectura del Fundamento de 1794 es comprender de qué manera el Yo es efectivamente igual al Yo, la clave de la ética es comprender cómo el deber constituye nuestro ser, y por tanto no se contrapone en forma abstracta con las condiciones empíricas (sino que, por el contrario, la Ética responde a la pregunta "¿cómo es posible la autoconciencia real?" -Binkelmann, 2006, p. 7-). Para ello debemos remitirnos a la doctrina de los impulsos de la Sittenlehre ( $\$ 12)$, donde Fichte muestra que el Yo puro del imperativo moral no agota el carácter del Yo (práctico), sino que debe estar en armonía con el Yo real (wirkliches Ich), en tanto el impulso puro (como exigencia meramente moral) debe entrar en concordancia con el impulso natural, por un lado, y con el impulso real (wirkliches Trieb), por el otro: ${ }^{24}$

Mi impulso básico (Grundtrieb) en cuanto ser puro y empírico, gracias al cual estas dos partes tan diferentes que me constituyen a mí mismo se convierten en una sola, es el impulso hacia la concordancia del Yo originario (ursprünglichen), determinado en la mera idea, y el Yo real (wirkliken Ich). Ahora bien, el impulso originario (Urtrieb), es decir, el puro más el natural en su unión, es un impulso determinado, va inmediatamente hacia algunas cosas; si mi estado real coincide con esta exigencia, entonces nace el placer; si la contradice, surge el displacer; y ambos no son sino el sentimiento inmediato de la armonía o disarmonía de mi estado real con lo exigido por el impuso originario (Fichte, 1977 , p. $136[193]) .^{25}$

El impulso básico o fundamental (Grundtrieb) no se confunde con el impulso originario ni con el punto en el cual la persona es colocada por su naturaleza (Yo real), sino que es al mismo tiempo "puro y empírico". Esta concordancia (Übereinstummung) tiene la forma de una armonía entre el Yo originario (Ursprüngliches Ich) y el Yo real (wirkliches Ich). Si esta armonía es vista como una imposición del impulso puro sobre el natural y el real (es el mundo el que se ha de ajustar a la exigencia de justicia y ha de ser transformado según los fines de la libertad), entonces nos mantenemos en el plano de la moral. Si el mundo no se adapta al deber y sigue sus propias leyes (cfr. Fichte, 2011, pp. 156-159) entonces tenemos que postular un mundo suprasensible, trascendente y juzgar el sensible en su nombre. Ahora bien, esto implicaría un doble dogmatismo: afirmar leyes del mundo independientes del Yo, y afirmar una ley moral "dada" en sí misma al Yo. Fichte caería en el dogmatismo que denuncia una

$23 \quad C f r$ la deducción del tiempo en Fichte (1994) p. 192.

24 "La exposición sistemática de la doctrina de los impulsos se encuentra especialmente en la Sittenlehre de 1798" (Binkelmann, 2006, p. 6). Para un análisis completo de esta doctrina, cfr. Binkelmann (2006) y Wood (2015).

25 Curiosamente, este pasaje, que discute la preeminencia del Yo puro determinado en la mera idea, es donde Hegel se detiene para demostrar tal preeminencia: "un fin final que nunca puede alcanzarse, una serie infinita, a través de cuya realización el Yo absoluto se volvería = al Yo" (Hegel, 1970a, pp. 75-76). 
y otra vez. ${ }^{26}$ Para evitar el dogmatismo metafísico debe también eludir el moralismo práctico: ni el mundo es dado ni el deber es dado, ambos deben necesariamente ser puestos por el Yo. Esa autoactividad del Yo es la determinación del hombre, es decir, su Bestimmung en el mundo, ética en sentido deleuziano, ${ }^{27}$ porque será buena en la medida en que la que las fuerzas que nos constituyen (puras y empíricas) compongan entre sí, es decir, expresen al Yo absoluto en su autoactividad constitutiva desde el punto de vista el un Yo real. La normatividad fichteana deja de ser inhumana, fanática y rígida para volverse perspectivista. ${ }^{28}$

\section{La tipología como segunda vida de los subjetivo}

De acuerdo a la perspectiva ética así planteada, el nudo conceptual de la Sittenlehre no puede estar puesto ni en el Yo puro ni en el Yo empírico, sino en la armonía (característica del impulso fundamental) entendida como composición o concordancia del Yo consigo mismo. Ahora bien, esta perspectiva nos obliga a desbordar el marco de la filosofía práctica y a considerar la perspectiva de las premisas fundamentales de la filosofía de Fichte tal como están expuestas en la introducción a la Ética:

Lo subjetivo y lo objetivo se reunifican o son considerados como armonizándose de tal manera que, primeramente, lo subjetivo debe seguirse de lo objetivo, lo primero debe regirse por lo último: yo conozco. Cómo llegamos a la afirmación de una armonía semejante, lo investiga la filosofía teórica. Si ambos son considerados como armonizándose de tal manera que lo objetivo debe seguirse de lo subjetivo, un ser debe seguirse de mi concepto (concepto de fin): yo obro. De dónde procede la admisión de una tal armonía, lo ha de investigar la filosofía práctica (Fichte, 1977, p. 21 [69-70]).

La armonía del Yo puro y del Yo empírico (subjetiva, en tanto perteneciente a la doctrina de los impulsos) se funda en la armonía -más profunda- de lo subjetivo y lo objetivo. ${ }^{29}$ Por eso, si bien la introducción "no dice nada de la ética [ni habla de las costumbres o la moral]" (Martin, 2015, p. 21), sí dice aquello indispensable para comprender la ética. Sólo la unión de la teoría y la práctica, como armonía de lo subjetivo y lo objetivo puede evitar que la ética fichteana caiga en el dogmatismo. Y no cae realmente, porque en realidad no existe la práctica escindida de la teoría, como tampoco existe la teoría sin la práctica (la perspectiva teórica es la que implica la afinidad del pensamiento con lo verdadero que Deleuze critica en torno a la imagen dogmática). La Doctrina de la ciencia es, en sentido estricto, teórico-práctica.

26 Sobre la crítica al dogmatismo que recorre toda la obra de Fichte, cfr. especialmente la Primera introducción a la doctrina de la ciencia (2016). Sobre el problema del dogmatismo en Fichte y Deleuze, en forma comparada, cfr. Ferreyra, 2018.

27 Aunque la distinción terminológica entre ética (Sittlichkeit) y moral (Moralität), tan importante por ejemplo en Hegel, está ausente en Fichte (que las utiliza como sinónimos), recurriremos a la distinción que sí hace Deleuze para distinguir dos posicionamientos divergentes respecto a la filosofía práctica (agradezco a Emiliano Acosta por la observación).

28 Este énfasis en la armonía entre el Yo originario y el Yo real para matizar el rigorismo que surge de una excesivo énfasis en el Yo puro, es compartido por Wood (2015, p. 107), pese a la impresión en contrario que la cita escogida por Breazeale generaba ( $c f r$. supra). Sobre la dificultades para hacer compatible estos puntos de vista "universal" y "individual", $c f r$. Breazeale (2012) pp. 188-189 y Neuhouser (1990), pp. 136-138.

29 No es por tanto una mera "coherencia de nuestro conocimiento" (Breazeale, 2012, p. 201). 
Esto exige romper con la clave de lectura de Gueroult en la que Deleuze se inspira para acusar a Fichte de moralista. Como vimos, Gueroult establecía una escisión en el trayecto fichteano entre un primado de la filosofía teórica y un primado de la práctica, que alcanzaría su máxima expresión en la ética (y con ello el sistema su culminación). De acuerdo a nuestro análisis, la cuestión es bien distinta: no se trata de un primado práctico sino de una armonía de lo teórico y lo práctico que se expresa en un imperativo ético de composición (y no primacía) del Yo puro con el Yo empírico (en el marco de la primacía del Yo puro respecto del empírico).

Como vimos, ésto nos acerca a la concepción de la ética (y no de la moral) sostenida por Deleuze. Lo interesante es que también podemos encontrar la referencia al doble aspecto teórico y práctico de la ética en la caracterización deleuziana:

Bueno y malo tienen entonces un primer sentido, objetivo, pero relativo y parcial: lo que conviene con nuestra naturaleza y lo que no conviene. Y, como consecuencia, bueno y malo tienen un segundo sentido, subjetivo y modal, que cualifica dos tipos, dos modos de existencia del hombre: será llamado bueno (o libre, o razonable, o fuerte) el que se esfuerce, tanto como esté en él, por organizar los encuentros, por unirse a lo que conviene con su naturaleza, por componer su relación con relaciones combinables $\mathrm{y}$, de esa manera, aumentar su potencia (Deleuze, 1981, pp. 34-35, yo subrayo “objetivo" y "subjetivo").

La ética deleuziana tiene entonces un sentido objetivo y uno subjetivo. El segundo es "consecuencia" del primero, pero, al mismo tiempo, el primero (sentido objetivo) es "relativo y parcial". Según este sentido objetivo, existen relaciones que a veces se componen y otras no se componen pero, en todo caso, son "naturales". Esto para Fichte es radicalmente cuestionable; para él, no podemos aceptar la naturaleza como un datum último: eso sería dogmatismo puro y confundiría las leyes de la naturaleza con las leyes (morales) de la libertad, distinción fundamental en el autor de la Doctrina de la ciencia. "Para el dogmatismo no hay moral. Sólo leyes de la naturaleza" (Fichte, 1977, p. 162 [219]). No se trata de una crítica meramente extrínseca, ya que este dogmatismo hace eco del resentimiento denunciado por Deleuze: "el hombre del resentimiento necesita concebir un no-Yo, después de oponerse a ese no-Yo, para ponerse al final como sí mismo" (Deleuze, 1962, p. 139). La práctica, desde esta perspectiva sesgadamente teórica, se limita a una evaluación de los contextos, a no entrar en situaciones imposibles, buscar lo bueno para nosotros, evitar lo malo, etcétera. Interesante, pero insuficiente. Reactivo. Es lo que Gueroult llamaba la parte práctica del Fundamento: el estudio de "la causalidad del Yo sobre el no-Yo desde el punto de vista de la causalidad del no-Yo sobre el Yo" (Gueroult, 1930, p. 291). En la perspectiva teórica, somos tristes engranajes de una maquinaria que nos excede, cuyos ciclos más terribles e inhumanos nos condenan a la vergüenza de ser hombres.

Por eso de acuerdo a Fichte la perspectiva teórica debe ser complementada por la práctica, donde lo subjetivo rige sobre lo objetivo: sólo así las relaciones de la experiencia no se toman como dadas. En el caso de Deleuze la cuestión es más incierta, ya que un primado del sentido subjetivo parece estar bloqueado por la muerte del sujeto implícita en su filosofía, que nos hace desconfiar de este primado tanto del Yo como de lo subjetivo. Pero, tal como expresa con claridad Frederic Rambeau, el sujeto vive en Deleuze una segunda vida. ${ }^{30}$ Esa segunda vida es la 
que late detrás del sentido subjetivo de lo bueno y lo malo en la ética de Spinoza. Un tipo o modo de existencia que se esfuerza por "organizar los encuentros, por unirse a lo que conviene con su naturaleza, por componer su relación con relaciones combinables y, de esa manera, aumentar su potencia" (Deleuze, 1981, p. 35). Para no ser dogmático, ese esfuerzo debe implicar un aspecto genético: organizar los encuentros no debe limitarse a una administración de lo dado y una gestión de sus posibles combinatorias, sino que debe incluir necesariamente la producción de las relaciones constitutivas mismas. La tipología como "ética de las maneras de ser" ( $c f r$. supra) se vuelve objeto de creación, de arte.

\section{La aplicabilidad de la ética deleuziana}

Hablamos de armonía y de composición como criterio ético, de Fichte a Deleuze. Sin embargo, no estamos dando cuenta del criterio de ese mismo criterio, que no puede ser trascendente o el juicio de Dios. ¿Cuándo podemos decir que algo se armoniza o compone? Fichte hablaba de placer y displacer como signos de la armonía o disarmonía del "estado real" y el "impulso originario" (1977, p. 136 [193]). Podría atribuirse, como quiso Hegel, a un eudemonismo secreto, ${ }^{31}$ o considerar al placer y displacer como efectos secundarios, meros fenómenos de lo que se trata, en realidad, de estudiar: el imperativo moral, el deber, etc. La lógica de estas páginas nos lleva a considerarlo desde el punto de vista deleuziano: como signo en el cuerpo de la alegría.

En Deleuze la alegría no es un comodín publicitario, ${ }^{32}$ sino que tiene un sentido técnico-filosófico: es el aumento de la capacidad de actuar (lo cual, como veremos, implica una concepción que no se confunde con otros sentidos del actuar y de la acción, y no implica cualquier acción empírica, ya que la mayoría de las "acciones" en el mundo son en realidad pasiones, efectos de los cuerpos exteriores). La armonía no es entonces una mera tranquilidad y quietud en lo concordante, sino una actividad, un movimiento característico: el del aumento de la potencia o capacidad de actuar. En el caso de Fichte, más allá, nuevamente, de sus deslices hacia una concepción de una beatitud quieta, esto es totalmente coherente con el espíritu de su sistema: el Yo puro debe caracterizarse por una autoactividad en enriquecimiento constante que, desde el punto de vista práctico (donde el Yo rige sobre el no-Yo) implica la exigencia de que el Yo empírico acompañe ese movimiento a través de nuevas formas (el yo empírico es el resultado de la acción del yo transcendental y su síntesis con el No-Yo). Si, como demuestra Fichte en el Fundamento del derecho natural y la Doctrina de la ciencia nova methodo, el cuerpo y la intersubjetividad se siguen necesariamente de esa actividad originaria del Yo, entonces las formas corporales y políticas deberán también acompañarlo. ${ }^{33} Y$ podrán, porque deben hacerlo, tal es el

de sujeto: el único sujeto son las subjetividades larvarias, y los yo disueltos. Por otro lado, no se queda en una destitución, su dinámica es creadora. Los sujetos que se disuelven se producen también en esta disolución (...) Al mismo tiempo que deshace el sujeto de sus predicados tradicionales, la disolución deleuziana le ofrece una segunda vida" (Rambeau, 2016, p. 19).

31 "Esas filosofías [las de Kant, Jacobi y Fichte] no sólo no se apartan de eudemonismo, sino que más bien sólo lo han perfeccionado al máximo" (Hegel, 1970a, p. 294).

32 Sobre las paradojas de la alegría en Deleuze $c f r$. Culp (2016) y Heffesse (2016).

33 Sobre la importancia de la intersubjetividad y el cuerpo, tanto en la obra de Fichte como en el corpus de 
imperativo moral que implica un enriquecimiento de las formas sociales y vitales, y a partir de la cual se puede valorar la armonía en sus diferentes formas. "¡Actuar! ¡Actuar! Para eso estamos aquí” (Fichte, 2002, p. 153).

En el caso de la ontología propiamente deleuziana (es decir, no entrelazada con la lectura de Nietzsche y Spinoza), el aumento de potencia como criterio ético nos remite a la relación entre los dos conceptos fundamentales de Diferencia y repetición: Idea e intensidad. ${ }^{34} \mathrm{El}$ elemento de potencialidad es el que encierra la clave del carácter dinámico de la Idea deleuziana, su différentiation como génesis de nuevas relaciones diferenciales (que, sin ese elemento, constituirían un estructuralismo estático). ${ }^{35} \mathrm{Si}$ consideramos que las Ideas son el aspecto trascendental de las relaciones sociales, biológicas, físicas, lingüísticas, etc., podemos decir que constituyen lo que en términos de Spinoza eran las relaciones naturales y sus leyes de composición y, en términos de Fichte, el elemento objetivo. La determinación ideal es lo que impide que esas leyes sean fijas e inmutables.

Ahora bien, para que haya alegría, para que haya placer, esas relaciones deben componer con nuestras relaciones individuales. Para dar cuenta de ello, hay que recurrir al segundo concepto fundamental de Diferencia y repetición: la intensidad. Deleuze señala el vínculo entre la potencialidad de la Idea y la potencia de la intensidad (1968a, p. 315). La intensidad es la energía que permite contrarrestar el buen sentido de las leyes empíricas que tienden a anular la diferencia y la energía (termodinámica). Deleuze nos dice que la intensidad es el principio de individuación, que precede al individuo ("la intensidad es individuante", 1968a, p. 317). ${ }^{36} \mathrm{El}$ concepto tardío de pliegue ${ }^{37}$ es el que permite comprender este carácter individuante de la intensidad: implicada en sí misma, la intensidad es el pliegue del tejido virtual que da cuenta de la potencia individual de transformar las relaciones objetivas. En ello consiste el proceso de subjetivación, que es la nueva vida del sentido subjetivo de la ética que permite interpretar en sentido deleuziano la práctica de Fichte como "regir lo objetivo por lo subjetivo". Componer las relaciones no es sólo adaptarse a las leyes objetivas (las que se vinculan a las relaciones Ideales, las que se explican en relaciones empíricas) sino transformarse a sí mismo, buscando ese pliegue que nos permite respirar. ${ }^{38}$ La tipología encuentra aquí su aspecto genético.

La intensidad es, en suma, la forma en que nos individuamos para componer con las Ideas biológicas, sociales y físicas que nos constituyen. La filosofía práctica en sentido fichteano (lo objetivo debe seguirse de lo subjetivo) implica este punto de vista de la filosofía deleuziana. Pero el aumento de potencia como criterio de la

sus estudiosos, cfr. Gaudio (2016), pp. 148-149, 196-202. Sobre la centralidad de la corporalidad, cfr. López Dominguez, V. (1996).

34 Nos separamos aquí del intento de desacoplar los escritos de los "60 de la "ética palpable de Spinoza: filosofía práctica y los escritos tardíos" (Kaufman, 2011, p. 119)

35 Sobre la Idea deleuziana, $c f r$. Deleuze (1968a), pp. 221-228, sobre el elemento de potencialidad pp. 226-228.

36 La individuación también está ligada al aumento de potencia, en tanto "la condición de la individuación reside en esta existencia de potenciales” (Simondon, 2005, pp. 202-203). De manera complementaria, si la potencia disminuye, las relaciones asimétricas constitutivas del plano intensivo se relajan, y el individuo muere ("la resolución de las tensiones es la muerte”, p. 204). Citamos a Simondon, ya que éste está a explícitamente a la base de la concepción deleuziana de individuación ( $c f r$. Deleuze, 1968a, p. 317).

37 En sus estudios sobre Foucault, Deleuze interpreta la subjetivación como un pliegue de las relaciones del saberpoder del Afuera (Deleuze, 1986, p. 106 y ss).

38 El pliegue es el arte de poder respirar, de rodearse de pliegues para poder vivir : “¿Cómo y en qué condiciones la línea de afuera podría devenir una línea de vida que no cae en el vacío, que no cae en lo irrespirable, que no cae en la muerte?" (Deleuze, 2015, p. 63). 
composición implica la perspectiva integral, absoluta, de la ontología. Hay aumento de potencia, composición, cuando hay correspondencia entre la potencialidad de la Idea (es decir, su desarrollo y actividad constitutivas) y la potencia de la intensidad (es decir, la energía que surge a través de la síntesis de elementos asimétricos). No nos dice quiénes somos, pero sí lo que debemos hacer en ciertos casos -lo cual incluye radicales transformaciones subjetivas- ${ }^{39}$

\section{Conclusión: una nueva armonía}

La afinidad entre las nociones de armonía y composición, consideradas ambas como la clave de una ética no moralista, se ha mostrado como una perspectiva de lectura heterodoxa pero potente para acercarse tanto al pensamiento práctico de Deleuze como al de Fichte a partir de la filosofía comparada. Permite, por una parte, ofrecer una alternativa exegética a las lecturas lineales y escatológicas del sistema de Fichte donde una moral formal, espiritual y trascendente dicta las normas del obrar, ignorando y despreciando el tiempo, el cuerpo y el mundo terrenal en el cual se desarrolla nuestra experiencia. El énfasis en la armonía permite jerarquizar el cuerpo y sus necesidades materiales, al mismo tiempo en que pone a lo espiritual como determinación inmanente que impulsa y vivifica el devenir empírico. En el caso de Deleuze, permite integrar las sugestivas concepciones éticas expuestas en torno a Spinoza, centradas en la composición de relaciones y el aumento de la capacidad de actuar, con el rigor de su ontología fundamental, evitando las trampas dogmáticas y enfatizando el rol del pliegue intensivo y la dinámica de las relaciones ideales.

Armonía, entonces, entre lo subjetivo y lo objetivo, entre el Yo empírico y el Yo puro en Fichte, que hace eco con la composición de las relaciones intensivas del individuo y las relaciones ideales que determinan cuerpos políticos y naturales en Deleuze. Estos ecos permiten pensar una ética inmanente y trascendental fichteana y un Deleuze no dogmático.

Queda sólo el interrogante que abren las trampas de la armonía, y obligan a plantearse los necesarios límites del afinismo radical que desborda y pone en riesgo la productividad de la filosofía comparada. En las últimas páginas de uno de sus libros más tardíos, El pliegue, Leibniz y el barroco, tituladas "una nueva armonía", Deleuze distingue dos tipos de armonía, una estrictamente leibnizana (un leibnizianismo forzado a sus límites por la violencia de la interpretación deleuziana) y una "nueva armonía discordante" (Deleuze, 1988, pp. 178-189). De acuerdo con la armonía leibniziana, las multiplicidades empíricas están subordinadas a un modelo, que podríamos llamar moral, que, es cierto, es en sí mismo dinámico, pero no por ello deja de tener una prioridad ontológica:

Una mónada produce acuerdos mayores y perfectos: aquellos en los que las pequeñas solicitaciones de la inquietud, lejos de desaparecer, se integran en un placer continuable, prolongable, renovable, multiplicable, proliferante, reflexivo, atractivo para otros acordes, y nos proporcionan la fuerza de ir siempre más lejos (Deleuze, 1988, p. 179).

39 Contra la afirmación de May de que los posestructuralistas "parecen extrapolar la inaceptabilidad de ciertas prácticas que le dicen a las personas quiénes son, a la inaceptabilidad de decirle a las personas lo que -al menos en algunos casos-deben hacer" (May, 1991, p. 51). 
La armonía fichteana tiene mucho de este modelo. Solamente, cada punto de vista es el aspecto real-natural del Yo está fundado en la unidad del Yo absoluto. Fichte suele ilustrar esa relación con la figura del círculo: "Del Yo como punto central son trazados infinitamente muchos infinitos radios" (Fichte, 1963, p. 36). Nuestra filosofía comparada podría hacernos pensar que también de esta manera debe caracterizarse la deleuziana. Sin embargo, en la última página de El pliegue, Leibniz y el barroco, Deleuze plantea su nueva armonía:

Cuando la mónada está atrapada entre dos series divergentes que pertenecen a mundos incomposibles (...) diríamos que la mónada, a caballo entre varios mundos, se mantiene medio abierta como por pinzas (...) La mónada no puede ya incluir al mundo entero como un círculo cerrado y modificable por proyección, sino que se abre hacia una trayectoria o una espiral en expansión que se aleja cada vez más del centro (Deleuze, 1988, p. 188).

Las multiplicidades son el prius ontológico del poskantismo deleuziano: "Mil mesetas tiene una ambición poskantiana (aunque resueltamente anti-hegeliana). El proyecto es «constructivista». Es una teoría de las multiplicidades por sí mismas" (Deleuze, 2003, p. 289). ${ }^{40}$ Esa base en las multiplicidades (la diferencia) hace que las composiciones se renueven sin cesar. La síntesis asimétrica entre Idea e intensidad se abre hacia una espiral que rompe con la figura del círculo y se aleja de cualquier centro posible o imaginable. La alegría es fugaz, sometida a variaciones continuas que exigen maneras perpetuamente innovadoras de plegar los cuerpos y recomponer las relaciones que nos determinan, desde afuera y desde adentro. Vivir en ese ruido, en ese caos, en esa violencia, es el desafío de la vida en los pliegues a la que nos invita la ética de Deleuze.

\section{Referencias bibliográficas}

Binkelmann, C. (2006): "Phänomenologie der Freiheit. Die Trieblehre Fichtes im System der Sittenlehre vom 1798", en Fichte-Studien, Band 27, pp. 5-21.

Bogue, R. (2007): Deleuze's Way, Essays in Transverse Ethics and Aesthetics, Aldershot, Ashgate.

Boltanski L.; Chiapello E. (2007): The New Spirit of Capitalism, New York, Verso.

Breazeale, D. (2012): “In Defense of Fichte's Account of Ethical Deliberation”, Archiv f. Gesch. d. Philosophie, vol 94, pp. 178-207.

Culp, A. (2016): Dark Deleuze, University of Minnesota Press, Minneapolis.

Deleuze, G. (2015): La subjetivación, curso sobre Foucault, tomo III, trad. P. Ires y S. Puente, Buenos Aires, Cactus.

Deleuze, G. (2008): En medio de Spinoza, trad. Equipo Editorial Cactus, Buenos Aires, Cactus.

Deleuze, G. (2003): "L'immanence: une vie...", en Deux régimes de fous et autres textes, Paris, Minuit, pp. 359-363.

40 En Fichte el rol de las multiplicidades es necesariamente subordinado: "nuestra actividad en tanto tal, como se sabe por lo [visto] anteriormente, no es ninguna multiplicidad, sino absoluta identidad pura, y ella sólo puede ser caracterizada por [su] relación a la resistencia. Por tanto, la multiplicidad que ha de ser distinguida tendría que ser una multiplicidad de la resistencia" (Fichte, 1977, p. 98 [151]). 
Deleuze, G. (2003): "Préface pour l'édition italienne de Mille Plateaux", en Deux régimes de fous et autres textes, Paris, Minuit, pp. 288-290.

Deleuze, G. (1988): Le pli, Leibniz et le baroque, Paris, Minuit.

Deleuze, G. (1981): Spinoza, philosophie pratique, Paris, Minuit.

Deleuze, G. (1969): Logique du sens, Paris, Minuit.

Deleuze, G. (1968a): Différence et répétition, Paris, PUF.

Deleuze, G. (1968b): Spinoza et le problème de l'expression, Paris, Minuit.

Deleuze, G. (1962): Nietzsche et la philosophie, Paris, PUF.

Deleuze, G. y Guattari, F. (1980): Mille plateaux, Paris, Minuit.

Descombes, V. (1988): Lo mismo y lo otro, trad. E. Bennrroch, Madrid, Cátedra.

Evans, F. (2016): “Deleuze's Political Ethics: A Fascism of the New?", Deleuze Studies, 10.1: pp. 85-99.

Ferreyra, J. (2018): “Fichte o Deleuze, ¿quién es el dogmático?”, en Valenciana, 21, pp. 257-288.

Fichte, J. (2016): Primera introducción a la Doctrina de la ciencia, en Primera y Segunda Introducción, Doctrina de la Ciencia nova methodo, Madrid, Xorki, pp. 41-67.

Fichte, J. (2011): El destino del hombre, trad. J. Gallo Reyzábal, Salamanca, Sígueme.

Fichte, J. (2002): Algunas lecciones sobre el destino del sabio, trad. F. Oncina Coves, Madrid, Itsmo.

Fichte, J. (1994): Wissenschaftslehre nova methodo, Hamburg, Meiner.

Fichte, J. (1977): Das System der Sittenlehre nach den Prinzipien der Wissenschaftslehre, en Gesamtausgabe der Bayerischen Akademie der Wissenschaften, Suttgart, Frommann (traducción al español de J. Rivera Rosales, Madrid, Akal [la paginación correspondiente a la traducción se indica entre corchetes a continuación de la paginación del original alemán]).

Fichte, J. (1975): Fundamento de toda la Doctrina de la ciencia, en Doctrina de la ciencia, trad. J. Cruz Cruz, Buenos Aires, Aguilar.

Fichte, J. (1963): Sobre el concepto de la Doctrina de la ciencia, trad. B. Bernabé Navarro, México, Centro de Estudios Filosóficos.

Fichte, J. (1845): Darstellung der Wissenschaftslehre aus dem Jahre 1801, en Samtliche Werke, II, Berlin, Veit.

Fonnesu, L. (1999): "Metamorphosen der Freiheit in Fichtes Sittenlehre”, en Fichte-Studien, Band 16, pp. 255-271.

Gaudio, M. (2016), "La concepción del Estado en el Fundamento del derecho natural de Fichte", tesis de Doctorado, Universidad de Buenos Aires.

Gaudio, M. (2004), "La dialéctica en el cuerpo propio de Fichte", en Revista de filosofía y teoría política. Actas de las $\mathrm{V}^{\mathrm{o}}$ Jornadas de Investigación en filosofía. Departamento de Filosofía de la Universidad Nacional de La Plata (9 al 11 de Diciembre de 2004). Disponible en: http://www.fuentesmemoria.fahce.unlp.edu.ar/trab_eventos/ev.96/ev.96. pdf.

Gueroult, M. (1930): L'évolution et la structure de la Doctrine de la Science chez Fichte, tomo 1, Paris, Les Belles Lettres.

Heffesse, S. (2016): "Un rizoma no nos va a salvar la vida", Ideas, revista de filosofía moderna y contemporánea, $\mathrm{N}^{\mathrm{o}} 4$, pp. 201-206.

Hegel. G.W.F. (1970a): Jenaer Schriften 1801-1807, Frankfurt am Main, Suhrkamp.

Hegel, G.W.F. (1970b): Grundlinien der Philosophie des Rechts, Frankfurt am Main, Suhrkamp. 
Ivaldo, M. (1999): "Die systematische Position der Ethik nach der Wissenschaftslehre nova methodo und der Sittenlehre 1798“, en Fichte-Studien, Band 16, pp. 237-254.

Jun, N. (2011): “Deleuze, Values and Normativity”, en N. Jun y D. Smith (eds.), Deleuze and Ethics, Edinburgh, Edinburgh University Press, pp. 89-107.

Kaufman, E. (2011): "Ethics and the World without Others", en N. Jun y D. Smith (eds.), Deleuze and Ethics, Edinburgh, Edinburgh University Press, pp. 108-122.

López-Domínguez, V. (1996): "El cuerpo como símbolo: la teoría fichteana de la corporalidad en Jena", en V. López-Domínguez (editora), Fichte 200 años después, Complutense, Madrid, pp. 125-141.

Martin, W. (2015): "Fichtes transzendentale Phänomenologie der Tätigkeit - Kommentar zu Fichtes Einleitung in die Sittenlehre”, en Merle J.-Ch. y Schmidt, A. Fichtes System der Sittenlehre, Frankfurt am Main, Klotermann, pp. 21-38.

May, T. (1991): The Moral Theory of Poststructuralism, University Park, Pennsylvania State University Press.

Neuhouser, F. (1990): Fichte's Theory of Subjectivity, Cambridge, Cambridge University Press.

Nietzsche, F. (1995): La genealogía de la moral, trad. A. Sánchez Pascual, Madrid, Alianza,

Simondon, G. (2005): L'individuation à la lumière des notions de forme et d'information, Paris, Millon.

Smith, D. (2011): "Deleuze and the Question of Desire: Towards an Immanent Theory of Ethics", en en N. Jun y D. Smith (eds.), Deleuze and Ethics, Edinburgh, Edinburgh University Press, pp. 123-150.

Wood, A. (2015): "Von der Natur zur Freiheit (System der Sittenlehre §§ 9-13)”, en Fichtes System der Sittenlehre, Frankfurt am Main, Klostermann, pp. 93-108. 